\title{
On the floral structure, seed development, and affinities of Deinostema, a new genus of Scrophulariaceae. $(2)^{*}$, **
}

\author{
By Takasi YamaZAKI***
}

山崎 敬：サワトウガラシ属とその類緣（2).アブノメサワトウガラシ及びオオアブノメの種子形成

Received January 22, 1953

1) Embryo sac development of Dopatrium junceum.

Structure of ovary and ovule. The globular ovary is bicarpellary and unilocular containing an indefinite number of anatropous ellipsoidal ovules borne on two lateral placentae, each one of which consists of two lobes (fig. I-3). The single integument is made up of three layers of cells in ventral side. In two-nucleate embryo sac stage, the cells of a nucellar epidermis are already completely destroyed. An innermost layer of the integument constructs the endothelium with the quadrilateral cells containing prominent nucleus and dense cytoplasm.

Structure of embryo sac. The development of the embryo sac corresponds to the Polygonum type of Maheshwari which is common in other Scrophulariaceae (figs. V-1,2,3). The mature embryo sac is fusiform in shape (fig. V-4). The endothelium invests the embryo sac partially, and the antipodal and the micropylar ends are free. Three conspicuous antipodal cells are angular and lie side by side. They contain dense cytoplasm and grow gradually after fertilization. In the time of the first endosperm division, they become most conspicuous and a few cells of the integument which cover the antipodal cells are broken down (figs. V-6, 7). The antipodal cells are gradually disintegrated after four-celled endosperm stage, but persist until the complete formation of the chalazal haustoria (fig. V-17).

Two polar nuclei meet in the center of the embryo sac. Two synergids are pyriform in shape, each containing a nucleus situated in its micropylar side and a large vacuole in its chalazal side, and are completely destroyed in the stage of the first endosperm division. The egg cell is pyriform in shape. Double fertilization is observed (fig. V-5). Two polar nuclei and a male nucleus fuse together to form a large globose secondary nucleus with a prominent nucleolus (fig. V-6).

Endosperm formation. The endosperm is of the cellular type. The embryo sac enlarges after fertilization. The first division of the primary endosperm nucleus

* No. 1 was published in the Journal of Japanese Botany Vol. 28, No. 5 (1953)

** I wish to express my thanks to Prof. Yudzuru Ogura for the careful reading of the manuscript.

*** Botanical Institute, Faculty of Science, University of Tokyo. 

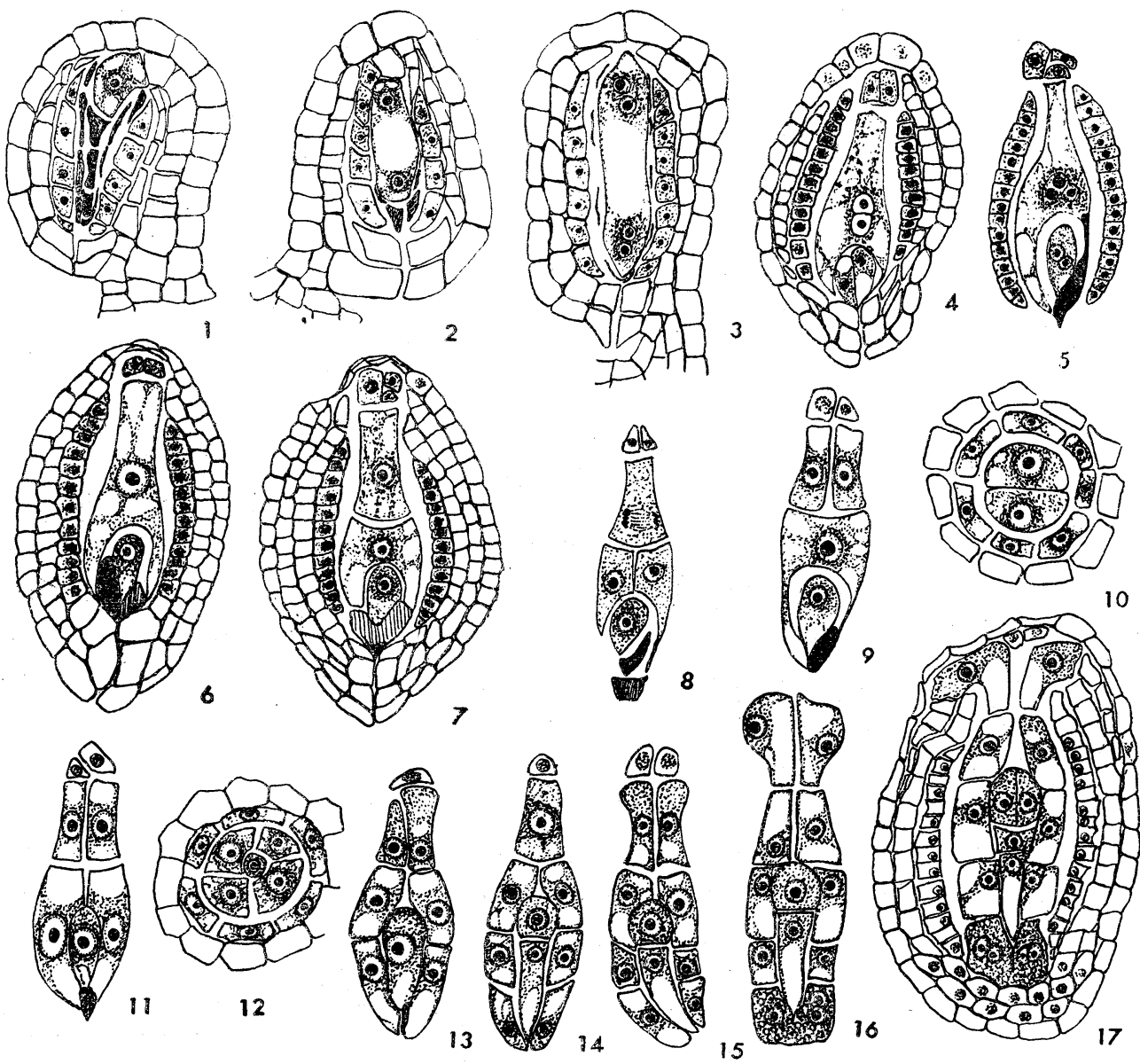

Fig. V. Dopatrium junceum. 1) Tetred, the upper three megaspores disintegrating. 2) and 3) Further developement of the megaspore. 4) Ovule showing the mature embryo sac: one of the synergids not shown. 5) Fertilization. 6) Ovule showing a secondary pole nucleus. 7) Formation of two chambered embryo sac. 8) Longitudinal division of the micropylar cham. ber. 9) Longitudinal division of the chalazal chamber. 10) Transverse section of the twocelled micropylar chamber at the same stage with fig. 9. 11) Further stage showing four-celled micropylar and two-celled chalazal chambers. 12) Transverse section of four-celled micropylar chamber at the same stage with fig. 11. 13) Transverse division in each of four micropylar cells results the formation of two tiers of four cells. 14) Lateral view of early stage in endosperm formation: proembryo divides into two cells. 15). Front view at the same stage with fig. 14. 16) Further stage showing the young chalazal and micropylar haustoria. 17) Ovule showing the fully developed chalazal and micropylar haustoria.

take place with a transverse wall to form a micropylar and a chalazal chambers (fig. V-7). Then, longitudinal divisions in both cells result four-celled chambers (figs. V-8, 9, 10). These two chalazal chambers do not divide further, but act as two uninucleate chalazal haustoria (fig. V-11). While two micropylar chambers undergo further longitudinal division perpendicularly to the previous plane of division 
resulting four cells (fig. V-12). Transverse division in each of these four cells result two tiers of four cells. The cells of micropylar tier enlarge, including deeply stained cytoplasm, and transform into four-celled micropylar haustoria. They immediately unite into a four-nucleate body (fig. V-16). The other tier of four cells undergo transverse division (figs. V-13, 14), and their further continuous transverse and longitudinal divisions produce the endosperm proper, which develops rapidly into a multicellular tissue and forms a ellipsoidal mass of cells. These cells are characterized by large vacuoles and lesser cytoplasm, but in the isthmus region near the micropylar haustoria, a few cells arranged in four-celled tiers are crashed and deeply stained (figs. VI-18).

When the endosperm is fully developed, the endothelial layer gradually disintegrates. The micropylar haustorium becomes a large globose mass, containing four
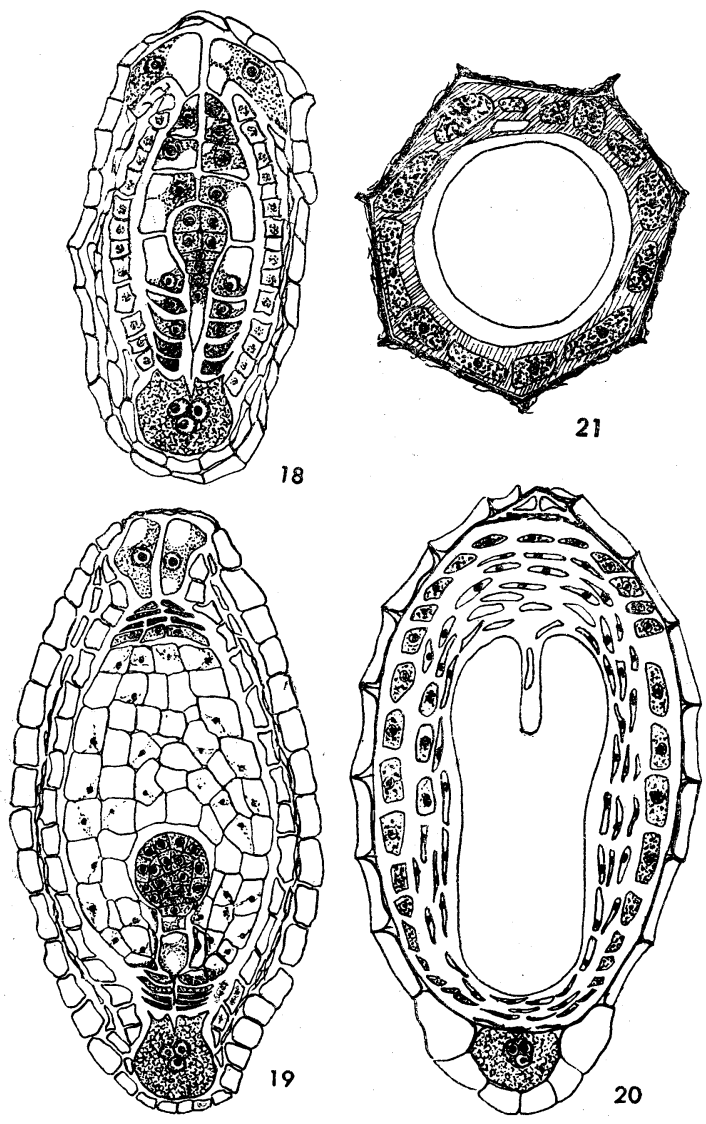

Fig. VI. Dopatrium junceum. 18) Further stage. The endosperm cells surrounded the sus. pensor are crushed. 19) Ovule showing the fully developed endosperm: the endothelial and inner integumental cells are crushed. 20) The immature seed. 21) Transverse section of mature seed. nuclei and deeply staining cytoplasm which is granular in appearance with minute vacuoles (fig. VI-19). This haustorium persists until in the mature seed and protrudes beyond the seed coat (fig. VI-20).

Each of two chalazal haustoria becomes a large hemispheric body containing a large vacuole in the side near the adjacent endosperm cells, denser cytoplasm and a conspicuous nucleus near the tip (fig. $\mathrm{V}-16)$. The large haustoria turns to a micropylar direction to penetrate a short distance into adjacent cells of the integument. Their nuclei are located frequently in the active portion of the haustoria (fig. VI-18). When the haustoria become older, they shrink and gradually disintegrate (fig. Vl-20).

As the embryo develops, the endosperm cells around the embryo are gradually broken down except the one outer layer which persists until the seed matures and the endothelial layer disintegrates completely. In the late development of the seed coat, the epidermal cells of the in- 
tegument enlarge greatly, and their lateral and inner tangental walls thicken (fig. VI-20). In the mature seed, the thin walls of outer side in the epidermal cells break down, thus leaving the thickened lateral walls as reticulate small projections on the surface of the seed.

The mature seed of Dopatrium junceum is ellipsoidal and consists of a straight embryo with two equal cotyledons surrounded by a layer of cutinized thick walled endosperm cells filled with granules. A lignized seed coat, with largely reticulated patterns, consists of a single layer of cells developed from the epidermis of ovule and of crushed remains of other integumental cells, and the spongy micropylar haustorium still remains at the micropylar end of the seed (figs. VI20, 21).

2) Embryo sac development of Deinostema violacea.

Structure of ovary and ovule. The ovoid ovary is, as common in other Scrophulariaceae, bicarpellary and bilocular, and has. axile placentation with numerous small ovules (fig. I-5). The anatropous ellipsoidal ovules have the single integument which is made up of three layers of cells in ventral side. In the mature embryo sac stage, the cells of a nucellar epidermis are completely destroyed, so that the mature embryo sac comes directly contact with the endothelium investing the embryo sac partially, but the antipodal and micropylar ends are free.

Structure of embryo sac. The developement of the embryo sac corresponds to the Polygonum type. The mature embryo sac is fusiform in shape (fig. VII-1). Three antipodal

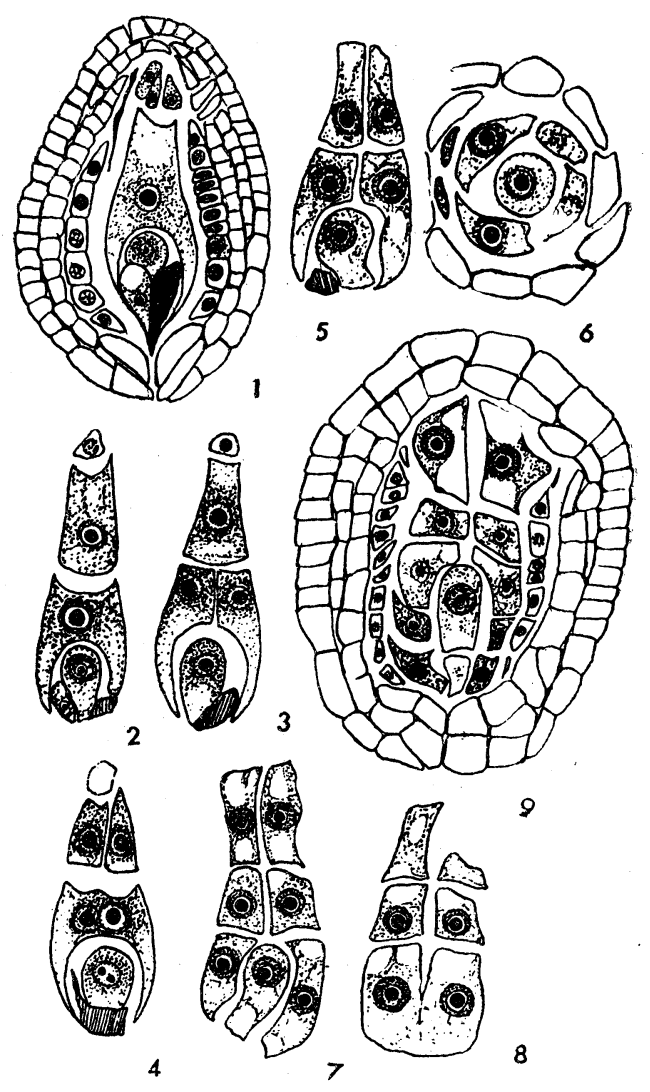

Fig. VII. Deinostema violacea. 1) The embryo sac after fertilization: one of the synergids is intact. 2) Formation of two chambered embryo sac. 3) Longitudinal division of the micropylar chamber. 4) The chalazal chamber undergo a longitudinal division perpendicularly to that of the micropylar chamber. Degenerating antipodal cell is seen. 5) Two micropylar cells undergo further longitudinal divisions perpendicularly to the previous plane of division resulting four cells. 6) Transverse section of four.celled micropylar chamber at the same stage with fig. 5. 7) Transverse divisions in each of four micropylar cel's result the formation of two tiers of four cells. 8). The same individual with fig. 7 , showing the micropylar cells. united in its lower part. 9) Ovule showing the stage in which the chalazal haustoria have begun to enlarge. 
cells are angular and lie side by side. Their nuclei are poor in chromatin and immediately disintegrate after fertilization. Two polar nuclei meet with each other in the center of the embryo sac' and fuse to give rise to a large globose secondary nucleus containing a prominent nucleolus. Two synergids are pyriform in shape, each containing a nucleus situated in its micropylar side and a large vacuole in its chalazal side. The egg cell is pyriform in shape. Disintegrating synergids persist through early endosperm divisions (figs. VII $-3,4$ ).

Endosperm formation. The pattern of the endosperm development is uniform, regardless in the normal or in the cleistogamous flowers. The endosperm development of the cleistogamous flowers are, however, better in growth than that of the normal flowers. The endosperm is of the cellular type. The embryo sac enlarges after fertilization. The first division of the primary endosperm nucleus is followed by a transverse wall to form a micropylar and a chalazal chambers (fig. VII-2). Then, longitudinal divisions in both cells result four cells (figs. VII-3, 4). Two chalazal cells do not divide further, but act as two uninucleate chalazal haustoria.

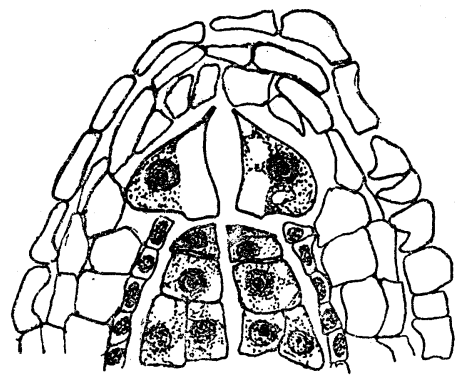

10

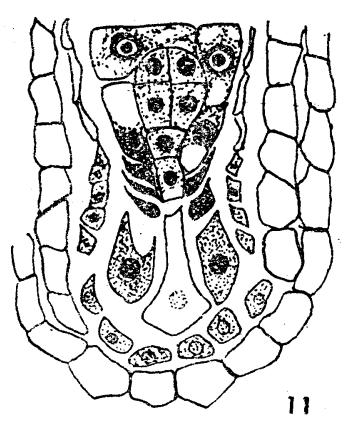

11

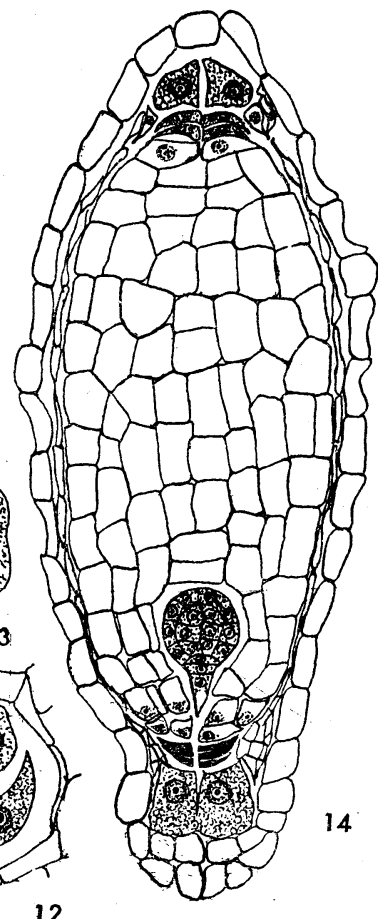

12

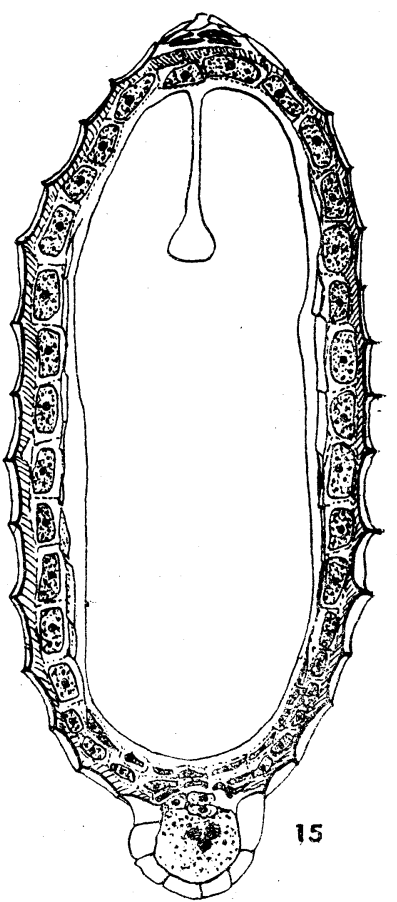

Fig. VIII. Deinostema violacea. 10) Fully developed chalazal haustoria. 11) Fully developed micropylar haustoria. The endosperm cells surrounded the suspensor are crushed. 12) Transverse section of the micropylar haustoria at the same stage with fig. 11, showing fourcelled haustoria. 13) Transversal section of the same haustoria in the individual of fig. 12, showing the micropylar haustoria united in its lower part. 14) Ovule showing the fully developed endosperm: the endothelial and inner integumental cells are completely crushed. 15) The mature seed. 
Two micropylar cells undergo further longitudinal division perpendicularly to the previous plane of division resulting four cells (figs. VII-5, 6). Transverse division in each of these four cells results two tiers of four cells (fig. VII-7). The micropylar tier of four cells enlarges and transforms into four-celled haustoria. Each of their two cells immediately unite in its lower part (fig. VII-8). The other tier undergoes transverse and longitudinal divisions and produces the endosperm proper, growing rapidly into a multicellular tissue and becoms ellipsoidal mass of cells (fig. VIII-14). These cells are characterized by large vacuoles and lesser cytoplasm, but, near the chalazal and micropylar haustoria, a few of four-celled tiers in the isthmus region are crashed down and deeply stained. (figs. VIII-10, 11, 14).

When the endosperm is fully developed, the endothelial layer gradually disintegrates. The micropylar haustoria become a large globose mass consisting of four cells. Each of these cells unites in its lower part and contains a large nucleus and deeply staining cytoplasm which is granular in appearance including many minute vacuoles (figs. VIII-12, 13, 14). When the haustoria become older, they shrink and unite to form a four nucleate body persisting until the seed matures (fig. VIII-15).

Each of two chalazal haustoria becomes a large hemispheric body containing a large vacuole in the side near the adjacent endosperm cells, denser cytoplasm and a conspicuous nucleus near the tip (figs. VII-9, VIII-10). The large haustoria penetrate a short distance in adjacent cells of the integument in a micropylar direction. Their nuclei are located more frequently in the active portion of the haustoria. When the haustoria become older, they shrink and gradually disintegrate.

As the embryo develops, the endosperm cells are gradually broken down around the embryo except a outer most layer which persists until the seed matures (fig. VIII-15). The endothelial layer disintegrates completely. In the late development of the seed coat, the epidermal cells of the integument enlarge greatly, and their lateral and inner walls thicken. In the mature seed, the outer walls of the epidermal cells, which still remain in thin membrane, break down, thus leaving the thickened lateral walls as reticulate small projections on the surface of the seed.

The mature seed of Deinostema violacea is ellipsoidal and consists of a straight embryo with two equal cotyledons, surrounded by a layer of cutinized thick walled endosperm cells filled with granules. A lignized seed coat, showing many reticulate patterns, consists of a single layer of cells developed from the epidermis of ovule and of crushed remains of other integumentaly cells, and the spongy micropylar haustorium remains at the micropylar end of the seed (fig. VIII-15).

3) Embryo sac development of Gratiola japonica.

Structure of ovary and ovule. The globular ovary is bicarpellary and bilocular and has axile placentation with numerous ovules. The ellipsoidal anatropous ovules have the single integument which is made up of three or four layers of cells. In the mature embryo sac stage, the cells of a nucellar epidermis are completely 
destroyed, so that the mature embryo sac comes in directly contact with the endothelium. The endothelium invests the embryo sac partially, and the antipodal and the micropylar ends are free.

Structure of embryo sac. The development of the embryo sac corresponds to the Polygonum type. The mature embryo sac is fusiform in shape (fig. IX-1). Three antipodal cells are angular and lie side by side. Their nuclei are poor in chromatin and immediately disintegrate after fertilization. Two polar nuclei meet in the center of the embryo sac and fuse to give rise to a large globose secondary nucleus. containing a prominent nucleolus. Two synergids are pyriform in shape, each containing a nucleus situated in its micropylar side and a large vacuole in its chalazal side. The egg cell is pyriform in shape.

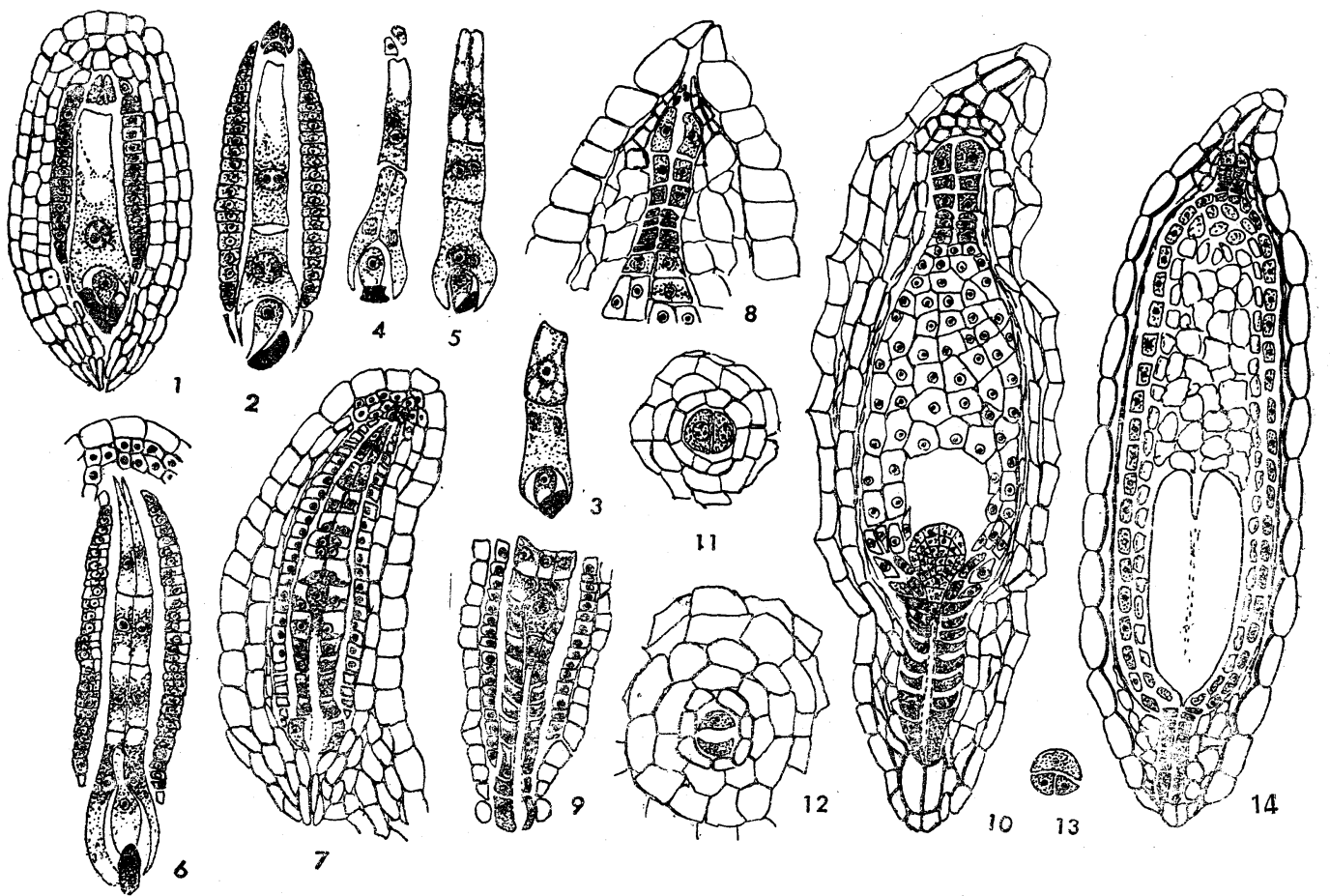

Fig. IX. Gratiola japonica. 1) The embryo sac after fertilization: one of the synergids is intact. 2) Formation of two chambered embryo sac. 3) Longitudinal division of the micropylar chamber. 4) and 5) Transverse divisions in the micropylar cells to form two-celled micropylar haustorium and two central cells. 6) Transverse divisions in the central cells resulting four tiers: the integumental cells of chalazal part contain large nuclei and dense cytoplasm. 7) Young stage of endosperm formation. 8) Chalazal part of young seed showing three tiers of proper chalazal haustoria and a few degenerated endosperm cells. 9) Micropylar part of young seed showing two micropylar haustorial cells situated in its basal portion and a few degenerated endosperm cells. 10) Ovule showing fully developed endosperm: the endothelial cells are crushed: the endosperm cells around the embryo are broken down. 11) Transverse section of chalazal haustorium: a tier consists of two cells. 12) Transverse section of micropylar isthmus region: a tier consists of two cells. 13) The same section consisting of three cells. 14) Transverse section of immature seed. 
Endosperm formation. The endosperm is of the cellular type. The embryo sac enlarges after fertilization and disintegrating synergids persist through the early endosperm divisions. The first division of the primary endosperm nucleus is followed by a transverse wall so as to form a micropylar and a chalazal chamber (fig. IX-2). One subsequent longitudinal division is observed to occur in the micropylar cell, thus the micropylar chamber consists of two cells (fig. IX-3). Then, in the chalazal chamber a longitudinal wall generally laid down perpendiculary (rarely parallel) to that in the micropylar chamber (fig. IX-4). Next, transverse walls are laid down in two micropylar cells. The result is a six-celled endosperm, which is made up of three tiers of two cells (fig. IX-5). Two cells of the chalazal tier undergo one or two transverse divisions and develop into the chalazal haustoria which are made up of two or three tiers of two cells containing dense cytoplasm. Two cells of the micropylar tier do not divide further and form uninucleate micropylar haustoria containing dense cytoplasm (figs. IX-6, 7). Through the seventh or eighth transverse division, the middle tier develops into linearshaped mass of cells consisting of many tiers of two cells (fig. IX-7). Then, a few middle tier of these cells undergo further continuous transverse and longitudinal divisions to produce the endosperm proper, which develops rapidly into a multicellular tissue and forms a oblong-shaped mass of cells. These cells are characterized by large vacuoles and lesser cytoplasm (fig. IX-10).

In the early stage of the endosperm development the integumental cells of chalazal part contain large unclei and dense cytoplasm, and become nutritive tissue. As the endosperm becomes fully developed, these cells are lost their contents and their walls thicken, thus the hypostase is formed. (fig. IX-10). A few cells of integument of micropylar end are lost their contents and their walls thicken, thus the epystase is formed (fig. IX-10).

Three or four tiers of two cells near the chalazal haustoria penetrate a short distance into the hypostase region and contain deeply stained cytoplasm, and they are probably considered to have a haustorial function (figs. IX-8, 10). The endosperm cells around the suspensor contain dense and deeply stained cytoplasm. They do not divide further and are pushed into the micropylar portion, thus the narrow six or seven tiers of two cells are formed (figs. IX-9, 10, 12 ; rarely three rows as in fig. 13). They are probably considered also to have a haustorial function.

L. M. Glišlć $(1933)^{*}$ in his account of Gratiola officinalis explained that the original two cells of micropylar tier were divided into six or seven tiers, but in my observation of $G$. japonica, the original micropylar tier does not divide and is situated in the basal portion of micropyle. The other haustorial micropylar cells are derived from the endosperm proper and may be identical with the cells of the isthmus region of Dopatrium junceum.

* L. M. Glišić, Zur Entwicklungsgeschichte von Gratiola officinalis L. in Bull. Inst. Jard. Bot. Univ. Beograd II-3: 129-152 (1933). 
When the haustoria become older, they shrink, but still persist in the mature seed protruding byond the seed coat (fig. IX-14). Proembryo has the elongated and filamentous suspensor (fig. IX-9). In later stage the narrow basal portion of the proembryonal tube becomes crushed and obliterated, while the broader terminal portion, which is destinated to give rise to the embryo proper, becomes favorably placed in the central mass of endosperm. As the embryo matures, the endosperm ells arec gradually broken down around the embryo, except an outer layer of thick-walled cells which persist until the seeds matures (fig. IX-14). The endothelial layer disintegrates completely. In the late development of the seed coat, the cells of the epidermis of the integument enlarge greatly and the lateral and inner walls of these cells thicken, while the outer walls of these cells which remain in thin, break down, thus leaving the thickened lateral walls as reticulate small projections on the surface of the seed.

The mature seed of Gratiola japonica is oblong and contains a straight embryo with two cotyledons, whose cells are filled with granules, surrounded by an outer layer of cutinized thick-walled endosperm cells filled with granules, and by some crushed remains of endosperm cells. A lignized seed coat, showing numerous reticulate patterns, consists of a single layer of cells developed from the epidermis of ovule and of crushed remains of other integumental cells.

\section{4) Differences of endosperm formation of these three genera.}

In Gratiola japonica, the fourth division of embryo sac is transverse, thus the result is a six-celled endospem which is made up of three tiers of two cells. The micropylar haustoria consist of two proper haustorial cells and of the narrow isthmus cells which are composed of six or seven tiers of two cells derived from endosperm proper. The chalazal haustoria consist of two or three tiers of two cells derived from the original chalazal chamber and of the narrow isthmus cells which are composed of three or four tiers of two cells derived from the endosperm proper. By the narrow haustoria arranging in many tiers, the oblong mass of endosperm, and the epystase and hypostase regions which are formed in micropylar and chalazal ends, Gratiola japonica remarkably agrees with Gratiola officinalis.

In Deinostema violacea, on the other hand, the fourth division of embryo sac is vertical, thus the result is a six-celled endosperm which is made up of two-celled chalazal tier and four-celled micropylar tiers. The micropylar haustoria becomes a large globose mass consisting of four cells which unite in its lower part, and the isthmus regions are composed of two or three tiers of four crushed cells. The chalazal haustoria are composed of two cells, each one of which becomes a large hemispheric body and penetrates into a micropylar direction. The endosperm proper becomes an ellipsoidal mass of cells. The endosperm formation of this kind is entierly different from that of Gratiola, and mostly agrees with that of Dopatrium junceum, although in the later the four cells of the micropylar haustorium unite into a four nucleate body in early stage and the antipodal cells are conspicuous. 